\title{
Morphometric Analysis of Bicipital Groove in Haryanvi Population
}

\author{
Neeru Ghalawat', Vivek Singh Malik², Vipin Kumar Garsa², Suresh Kanta Rathee ${ }^{3}$ \\ ${ }^{1}$ Assistant professor, Department of Anatomy Pt. B. D. Sharma University of Health Sciences Rohtak, Haryana, India, ${ }^{2}$ Professor, Department of Anatomy \\ Pt. B. D. Sharma University of Health Sciences Rohtak, Haryana, India, ${ }^{3}$ Senior Professor, and Head, Department of Anatomy Pt. B. D. Sharma University \\ of Health Sciences Rohtak, Haryana, India.
}

\section{Abstract}

Introduction: Bicipital groove (BG) in the proximal part of humerus is an indentation formed between the lesser and greater tubercle forms the lateral edge of lesser tubercle forms the medial border of bicipital groove. It contains the long head of the biceps brachii muscle, its synovial sheath and an ascending branch of the anterior circumflex humeral artery. The depth and width are very important in retention of tendon of biceps. Several authors reported greater incidence of sublaxation and dislocation of tendon of biceps when the BG is shallow. Morphometry of bicipital groove may influence the functions of surrounding structure leading to various pathological condition. BG is important landmark for replacement of prosthesis of shoulder. Thus knowledge of BG is highly useful in prosthetic sizing, positioning and designing. Aim and objectives - To study the morphometry of bicipital groove (BG). Subjects and Methods: Present study was done on 50 humeri in PGIMS Rohtak in which 25 were of right side and 25 left side. The length, width, depth of BG and the length of the medial and lateral wall of intertubercular sulcus were measured using digital Vernier caliper. Data was recorded separately for right and left humeri then it was analyzed statistically using independent $t$ test, $\mathrm{p}$ value $<0.05$ were considered significant. The data was presented as mean \pm SD. Results: In present study above stated parameters were measured which came out to be statistically insignificant except the width of BG, which showed the statistical difference. The $\mathrm{p}$ value for the width of BG was < 0.05 . Conclusion: Knowledge of BG is highly useful in prosthetic sizing, positioning and designing. The present study is an attempt to determine the morphometric parameters of BG in terms of length of medial wall, lateral wall, length of BG, width and depth of BG. The data on morphometry of BG will be of utmost use for radiologists, orthopedic surgeons and physiotherapists.

Keywords: Bicipital groove (BG), biceps brachii, intertubercular sulcus.

Corresponding Author: Dr. Neeru Ghalawat, Assistant professor, Department of Anatomy Pt. B. D. Sharma University of Health Sciences Rohtak, Haryana, India.

Email: drneeru465@gmail.com

Received: March 2020

Accepted: March 2020

\section{Introduction}

Bicipital groove (BG) in the proximal part of humerus is an indentation formed between the lesser and greater tubercle forms the lateral edge of lesser tubercle forms the medial border of bicipital groove.$^{[1]}$ It contains the long head of the biceps brachii muscle, its synovial sheath and an ascending branch of the anterior circumflex humeral artery. ${ }^{[2]}$ From functional point of view, the most important region is the intertubercular sulcus. The coracho-humeral ligament directly overlies the transverse humeral ligament and is continous with rotator cuff. The tendon of the long head of biceps play an important role in maintaining the alignment of the head of the humerus with in the glenoid cavity of scapula in movment involving the use of the arm and forearm. The humerus moves on the tendon of the long head of the biceps in all movment of the upper extremity. ${ }^{[3-5]}$ Sublaxation and dislocations of the biceps tendon are more common in people with a shallow intertubercular sulcus. ${ }^{[6,7]}$ Morphometry of bicipital groove may influence the functions of surrounding structure leading to various pathological condition. ${ }^{[8,9]}$ Rockwood and Mastsen mentioned that humans are unique among primates in presenting marked variation in the configuration of bicipital groove. ${ }^{[10,11]} \mathrm{BG}$ is important landmark for replacement of prosthesis of shoulder. Thus knowledge of BG is highly useful in prosthetic sizing, positioning and designing. ${ }^{[12]} \mathrm{BG}$ also acts as an important landmark for placement of lateral fin of prosthesis in shoulder in shoulder arthroplasty and humeral head replacement in fractures of upper end of humerus. ${ }^{[13]}$ Anterior shoulder pain affects large masses of people. Lesion affecting the tendon of long head of biceps brachii have been postulated to be among the most frequent causes of pain and disability in shoulder. This pain may be caused by rotator cuff, supraspinatus and biceps tendon diseases. ${ }^{[14]}$ Hence an attempt has been made to examine the length, width, depth of BG and length of medial and lateral wall of BG.

\section{Subjects and Methods}

Present study was done on 50 humeri in PGIMS Rohtak in which 25 were of right side and 25 left side. The age and sex 


\section{Ghalaweat et al; Marphametric Analysis of Bicipital Graave}

were not determined. These bones were unpaired. Humeri with gross evidence of disease were excluded from the study. Than the following parameters were measured using digital Vernier caliper.

1) Length of $B G$ was measured as the maximum vertical distance between the tubercles to the end of the medial lip of bicipital groove.

2) Depth of BG was measured between the greater and lesser tubercle.

3) Width of BG was measured between the two tubercles.

4) The length of medial and lateral lip was measured from the tubercles to respective lips of BG.

Data was recorded separately for right and left humeri then it was analyzed statistically using independent $t$ test. P-value $<0.05$ were considered significant. The data was presented as mean $\pm \mathrm{SD}$.

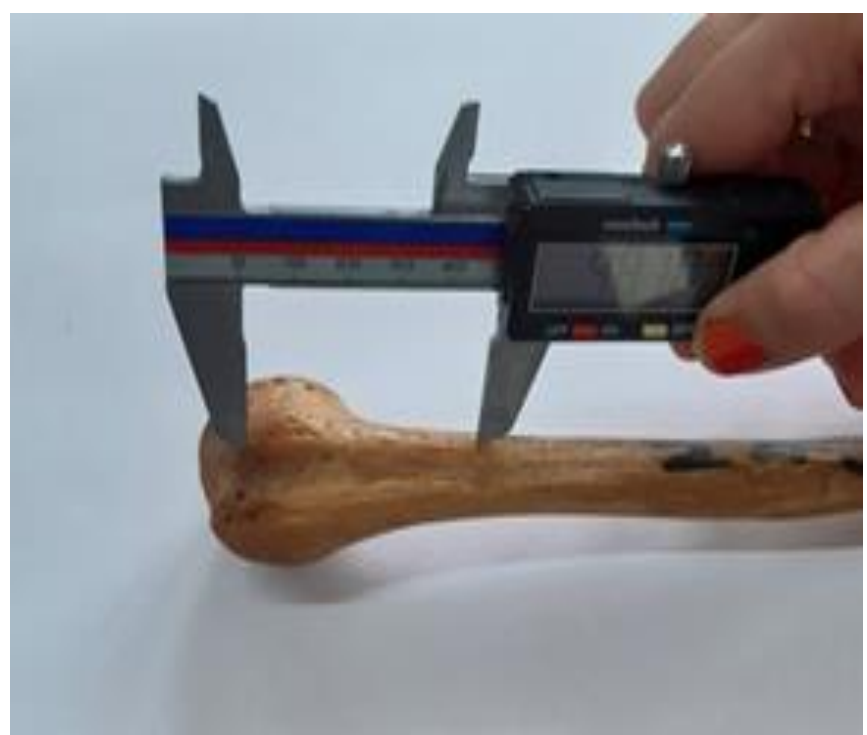

Figure 1: Showing the measurement of MWL

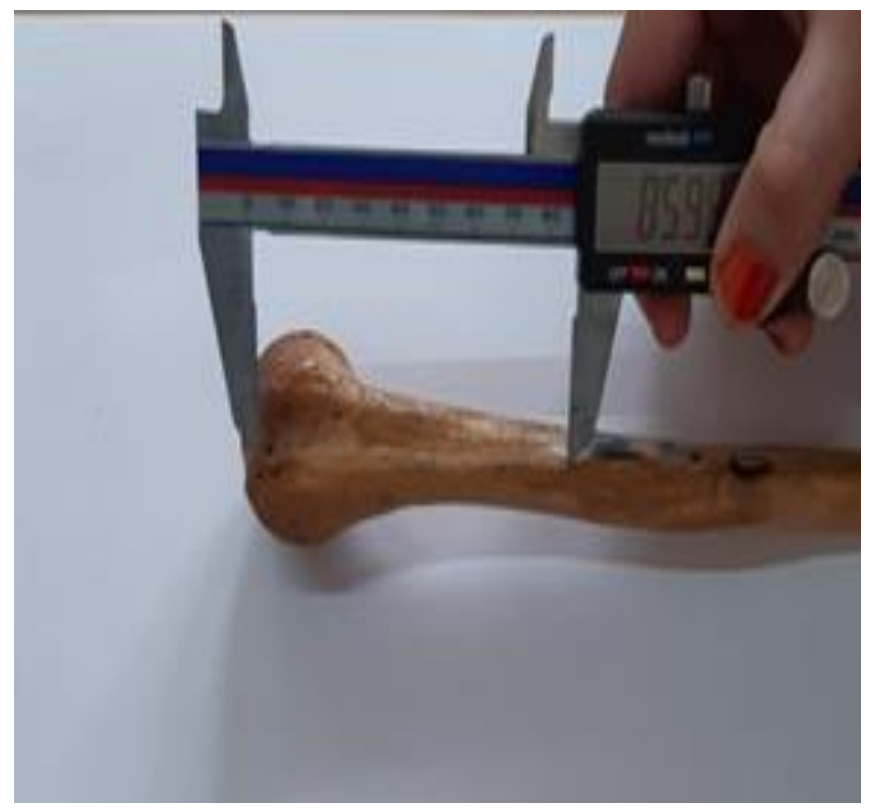

Figure 2.Showing the measurement of LWL

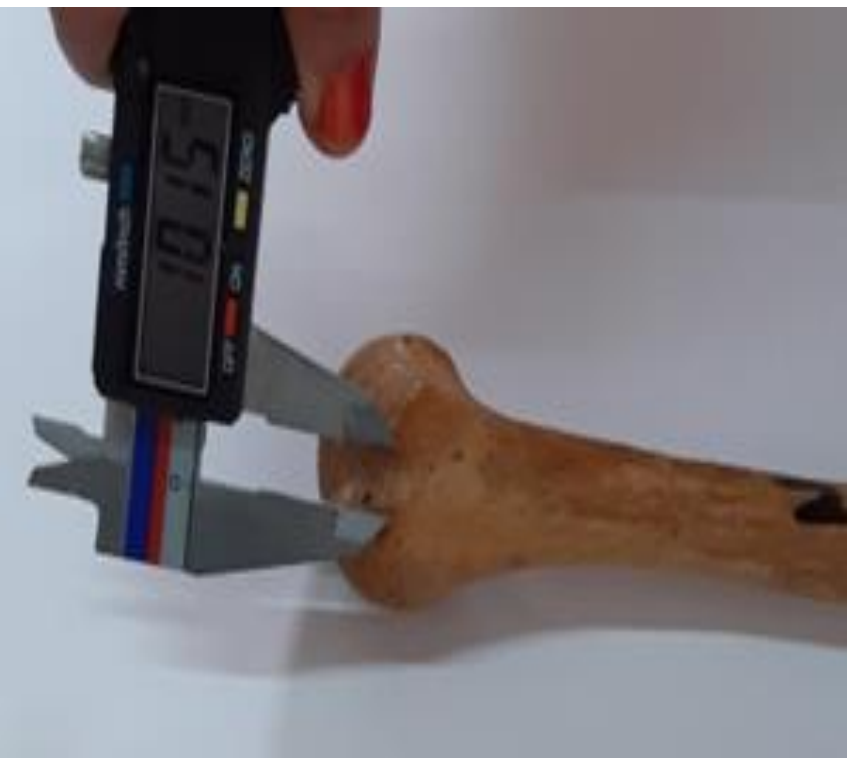

\section{Figure 3.Showing measurement of width of BG}

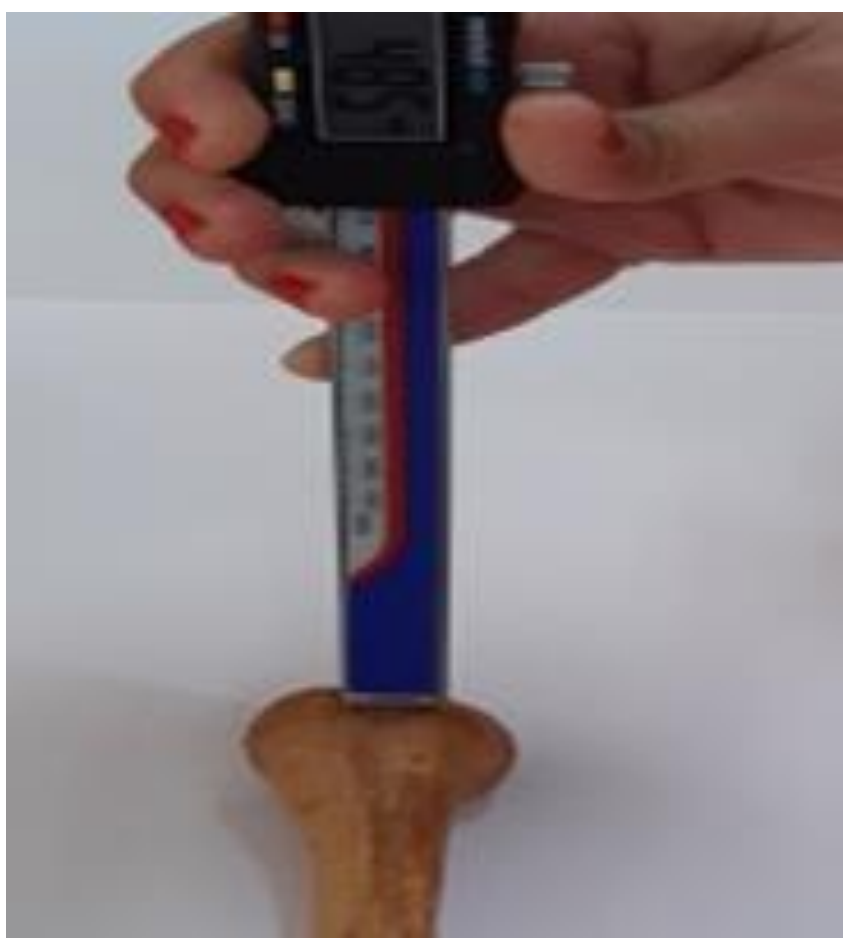

Figure 4.Showing the measurement of depth BG

MWL $=$ medial wall length

$\mathrm{LWL}=$ lateral wall length

$\mathrm{BG}=$ bicipital groove

\section{Results}

Table 1: Showing morphometric measurements of BG.

\begin{tabular}{|l|l|l|l|l|}
\hline $\begin{array}{l}\text { Sr. } \\
\text { no }\end{array}$ & Parameters in $\mathbf{~ m m}$ & Right side & Left side & $\begin{array}{l}\text { P } \\
\text { value }\end{array}$ \\
\hline 1. & Length of BG & $70.96 \pm 11.5$ & $69.55 \pm 6.96$ & 0.54 \\
\hline 2. & Width of BG & $13.03 \pm 1.46$ & $12.02 \pm 1.75$ & 0.03 \\
\hline 3. & Depth of BG & $3.71 \pm 0.71$ & $3.82 \pm 0.65$ & 0.57 \\
\hline 4. & Length of lateral wall & $96.79 \pm 10.59$ & $97.05 \pm 10.21$ & 0.93 \\
\hline 5. & Length of medial wall & $65.98 \pm 10.50$ & $65.85 \pm 6.15$ & 0.95 \\
\hline
\end{tabular}




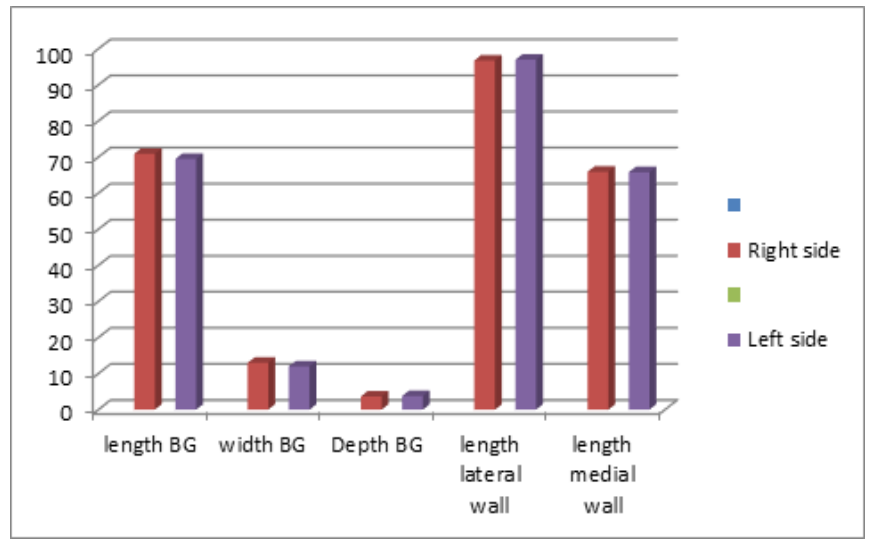

Graph 1. Showing the various parameters of BG.
Morphometric measurements of the BG were carried out on 50 humeri. The mean length, width, depth of $\mathrm{BG}$ and the mean length of the medial and lateral walls of BG were measured, which have been computed as shown in [Table 1].

\section{Discussion}

The bicipital groove in the humerus lodges the tendon of biceps brachii in a tunnel formed by the fibrous band i.e. transverse humeral ligament. Morphometric studies carried out by various authors has been compared with present study as depicted in [Table 2].

\begin{tabular}{|c|c|c|c|c|c|c|c|c|c|c|c|}
\hline & $\begin{array}{l}\text { Wafae } \\
\text { et } \\
\text { al.g, }\end{array}$ & $\begin{array}{l}\text { Cone } \\
\text { et } \\
\text { al, }{ }^{[16]}\end{array}$ & $\begin{array}{l}\text { Abboud } \\
\text { et al, }{ }^{[14]}\end{array}$ & Rt & $\mathbf{L t}$ & Rt & Lt & $\mathbf{R t}$ & $\mathbf{L t}$ & Rt & $\mathbf{L t}$ \\
\hline $\begin{array}{l}\text { Length } \\
\text { BG }\end{array}$ & 81 & - & - & $86 \pm 10.1$ & $83.3 \pm 11.5$ & $85 \pm 09$ & $83 \pm 10.1$ & $84.79 \pm 5.8$ & $87.3 \pm 6.40$ & $70.96 \pm 11.5$ & $69.5 \pm 6.9$ \\
\hline $\begin{array}{l}\text { Width } \\
\text { BG }\end{array}$ & 10.1 & 8.8 & - & $8.3 \pm 2.4$ & $8.7 \pm 2.2$ & $9.0 \pm 2.1$ & $8.9 \pm 1.1$ & $6.8 \pm 1.01$ & $7.74 \pm 1.96$ & $13.03 \pm 1.46$ & $12.02 \pm 1.75$ \\
\hline $\begin{array}{l}\text { Depth } \\
\text { BG }\end{array}$ & 4 & 4.3 & 5.1 & $4.7 \pm 2$ & $4.2 \pm 1.6$ & $5.0 \pm 1$ & $6.0 \pm 1$ & $4.21 \pm 0.58$ & $4.21 \pm 0.58$ & $3.71 \pm 0.71$ & $3.82 \pm 0.65$ \\
\hline $\begin{array}{l}\text { Length } \\
\text { MW }\end{array}$ & - & - & - & - & - & $23 \pm 4$ & $24 \pm 5$ & $24.22 \pm 1.02$ & $23.31 \pm 2.21$ & $65.98 \pm 10.50$ & $65.85 \pm 6.15$ \\
\hline
\end{tabular}

$\mathrm{BG}=$ bicipital groove, $\mathrm{LW}=$ lateral wall, $\mathrm{MW}=$ medial wall

The morphometry of BG is likely to be influenced by the nature of manual work a person does. In manual workers the pressure on the biceps tendon will be higher on the right side than the left side and vettivel et $\mathrm{al}^{\left[{ }^{[8]}\right.}$ reported such morphometric change in the BG. As compared to other studies, length of BG in present study was found to be $70.96 \pm 11.5$ on right side and $69.5 \pm 6.9$ on left side, which was less on both the sides but it was statistically insignificant. Depth of BG in present study was a $3.71 \pm 0.71$ on right side and $3.82 \pm 0.65$ on left side which was again less than other author's study, but again it was statistically insignificant. In present study the length of the lateral wall was found to be $96.79 \pm 10.59$ on right side and $97.05 \pm 10.21$ on left side which was quite more than studies done by Rajni $S$ et al in which length of the lateral wall was $31 \pm 6 \mathrm{~mm}$ on the right side and $31 \pm 5 \mathrm{~mm}$ on the left side, Yamini et al reported the length of the lateral wall to be $32.05 \pm 2.21$ on the right side and $31.12 \pm 0.24$ on left side. In the case of medial wall, in present study it was found to be more than other author studies, it was $65.98 \pm 10.50$ on right and $65.85 \pm 6.15$ on left side whereas in study done by Rajni $S$ et al. it was $23 \pm 4$ on right side and $24 \pm 5$ on left side, Yamini et al, reported the length of medial wall to be $24.22 \pm 1.02$ on right side and $23.31 \pm 2.21$ on left side. So both lateral and medial wall findings were also statistically insignificant.

The depth and width are very important in retention of tendon of biceps. Several authors reported greater incidence of sublaxation and dislocation of tendon of biceps when the BG is shallow. In present study width of BG was found to be more than that of other authors. It was found to be $13.03 \pm 1.46$ on right side and $12.02 \pm 1.75$ on left side which was statistically significant. In the present study measurement of the width was taken between the two tubercles whereas in studies done by other authors measurement was taken between the medial and lateral lips of the BG. In their studies results were statistically insignificant whereas result of the present study came out to be statistically significant.

\section{Conclusion}

The present study is an attempt to determine the morphometry of BG in terms of length of medial wall, lateral wall, length of BG, width and depth of BG. The data on morphometry will be of utmost use for radiologists, orthopedic surgeons and physiotherapists.

\section{References}

1. Standring. S Grays Anatomy: the anatomical basis of clinical practice, 40th edition, Edinburgh: Elsevier Churchil Livingstone: 2008:796-798

2. Ellis H, Healy JC, Johnson D, Williams A. Gray's anatomy. In: Standring S, editor. The Anatomical Basis of Clinical Practice. 39th edition. Spain: Churchill Livingstone; 2006:823-32.

3. Basmajian JV, Latiff A. Integrated actions and functions of the chief flexors of the elbow: a detailed electromyography analysis. J Bone Joint Surg Am. 1997;39-A(5):1106-1118.

4. Sullivan WE, Mortensen OA, Miles M, Greene LS. Electromyographic studies of $\mathrm{M}$. biceps brachii during normal voluntary movment at the elbow. Anat Rec. 1998; 107(3):243-251.

5. Travill A, Basmajian JV. Electromyography of the supinators of the forearm. Anat Rec. 2006;139:557-560.

6. Slatis P, Aalto K. Medial dislocation of the tendon of the head of the biceps brachii. Acta Orthop Scand 1996;50:73-7.

7. Nevaiser RJ. Lesions of the biceps and tendinitis of the shoulder. 


\section{Ghalaunat et al; Marphametric Analysis of Bicipital Graave}

Orthop Clin North Am 1999;11:343-8.

8. Vettival S, Indrasingh I, Chandi G, Chandi SM. Variations in the intertubercular sulcus of the Humerus related to Handedness. J. Anat. 1992;(180),321-6.

9. Rasch PJ, Burke RK. Kinesiology and Applied anatomy, Lea and Febiger, Philadelphia, Pa, USA, 5th edition, 1974.

10. Robertson DD, Yuan J, Bigliani LU, Flatow EL, Yamaguchi K. Three dimensional analysis of the proximal part of the humerus: Relevance to arthroplasty. J Bone and Joint Surg. 2000; 82(11):1594-1602.

11. Rockwood CA, Masten FA. The Shoulder. Philadelphia, W. B. Saunders Company. 1990; 2.

12. Robertson DD, Yuan J, Bigliani LU, Flatow EL, Yamaguchi K. Three dimensional analysis of the proximal part of the humerus: Relevance to arthroplasty. J Bone Joint Surg. 2000; 82(11):15941602.

13. Itamura J, Dietrick T, Roidis N, Shean C, Chen F, Tibone J. Analysis of the bicipital groove as a landmark for humeral head replacement. J of Shoul Elb Surg. 2002; 4(2) 322-326.

14. Abboud JA, Bartolozzi AR, Widmer BJ, DeMola PM. Bicipital groove morphology on MRI has no correlation to intra-articular biceps tendon pathology. J Shoul Elb Surg. 2010;19(6):790-794.

15. Wafae N, Atencio Santamaria LE, Vitor L, Pereira LA, Ruiz CR, Wafae GC. Morphometry of the human bicipital groove (sulcus intertubercularis). J Shoul Elbow Surg. 2010;19(1):65-68.

16. Cone RO, Danzig L, Resnick D, Goldman AB. The bicipital groove: radiographic, anatomic and pathologic study. AJR Am J Roen. 1983;141:781-88.

17. Murlimanju BV, Prabhu LV, Pai MM. Anthropometric study of the bicipital groove in Indians and clinical implications. Chang Gung Med J. 2012;35(2):155-59.

18. Rajani S, Man S. Review of bicipital groove morphology and its analysis in North Indian Population. ISRN Anat. 2013;23:1-7.

19. Yamini S.R. et al. Morphometric study on bicipital groove among south Indian population. JCDR. 2016;10(7):1-3.

Copyright: (C) the author(s), 2020. It is an open-access article distributed under the terms of the Creative Commons Attribution License (CC BY 4.0), which permits authors to retain ownership of the copyright for their content, and allow anyone to download, reuse, reprint, modify, distribute and/or copy the content as long as the original authors and source are cited.

How to cite this article: Ghalawat N, Malik VS, Garsa VK, Rathee SK. Morphometric Analysis of Bicipital Groove in Haryanvi Population. Acad. Anat. Int. 2020;6(1):26-29.

DOI: dx.doi.org/10.21276/aanat.2020.6.1.6 